\title{
Pregnancy outcome in gestational diabetes mellitus
}

\section{Bajracharya $A^{1}$, Saha $R^{2}$, Shakya $A^{3}$}

${ }^{1}$ Anu Bajracharya, Lecturer; ${ }^{2}$ Rachana Saha, Professor; ${ }^{3}$ Archana Shakya, MD Resident; Department of Obstetrics and Gynaecology, Kathmandu Medical College Teaching Hospital, Kathmandu, Nepal

\begin{abstract}
Background: Gestational diabetes mellitus is a metabolic disorder defined as glucose intolerance with the onset or first recognition during pregnancy. Gestational diabetes mellitus is associated with higher incidence of maternal diabetes mellitus later in life. It poses a risk to the pregnant woman and to the fetus. Hence, it is imperative for an early detection and management of the disease to ensure better maternal and foetal outcomes.

Objective: To assess the prevalence of gestational diabetes mellitus and to analyze the maternal and perinatal outcomes of gestational diabetes mellitus patients who delivered in the hospital during the study period.

Methods: A hospital based descriptive observational study was conducted at Kathmandu Medical College Teaching Hospital for a period of one year from $1^{\text {st }}$ January 2013 to $31^{\text {st }}$ December 2013 . All the cases of gestational diabetes mellitus were included in the study. Patients were followed from the time of admission to the time of discharge after delivery. Pertinent information obtained were demography, gestational age at diagnosis and delivery, pregnancy complications, intervention and perinatal morbidity and mortality.

Results: Out of 2845 deliveries, 45 patients were diagnosed as gestational diabetes mellitus and admitted during the period of study. The prevalence of gestational diabetes mellitus was $1.58 \%$ in this hospital. The most common maternal and neonatal complications were gestational hypertension (20\%), hypoglycemia (8.89\%) and macrosomia (8.89\%) respectively.

Conclusion: This study is important in providing information about the maternal and neonatal outcomes of gestational diabetes. By proper monitoring and good glycaemic control during the antenatal period, the adverse maternal and neonatal complications of gestational diabetes mellitus can also be reduced.
\end{abstract}

Key words: Gestational diabetes mellitus, Maternal outcome, Neonatal complication

\section{INTRODUCTION}

G estational diabetes mellitus (GDM) is defined as any degree of glucose intolerance first time detected during pregnancy ${ }^{1}$. Depending on the type of population and the diagnostic criteria used, gestational diabetes is said to complicate $1-16 \%$ of all pregnancies ${ }^{2}$. If GDM is not properly treated, there is an increased risk of adverse maternal complications like pre-eclampsia, pregnancy induced hypertension, increased incidence of operative deliveries, obstructed labour and development of diabetes mellitus later in life, foetal complications

Address for correspondence

Dr. Anu Bajracharya

Lecturer

Department of Obstetrics and Gynaecology

Kathmandu Medical College Teaching Hospital,

Kathmandu, Nepal

E-mail: dr.anubajracharya42@gmail.com like macrosomia, polyhydramnios, preterm labour, respiratory distress, unexplained intrauterine foetal death, traumatic delivery and neonatal complications like hypoglycaemia, jaundice, polycythaemia, hypocalcaemia and hypomagnesaemia ${ }^{3}$. According to a large-scale multinational epidemiologic study, the risk of adverse maternal and perinatal outcomes constantly increased as a function of maternal glycaemia at 2428 weeks of gestation. No threshold for the majority of these complications was found, but prevention and early detection of GDM is a growing health concern ${ }^{4}$. In majority of women with gestational diabetes, glucose tolerance returns to normal but one-third to two-thirds of women will have glucose intolerance in subsequent pregnancies ${ }^{5,6}$. Recently, the effect of screening and clinical management of GDM on antenatal, neonatal and perinatal outcome has been proved to be beneficial?.

Since very little data is available regarding gestational diabetes in our context, this study was done to 
analyse maternal and foetal outcomes in pregnancies complicated by GDM.

\section{METHODS}

This hospital based observational and descriptive study was carried out in Kathmandu Medical College Teaching Hospital (KMCTH), in the Department of Obstetrics and Gynaecology over a period of one year from $1^{\text {st }}$ January 2013 to $31^{\text {st }}$ December 2013. All women diagnosed with GDM and delivered at KMCTH were included in the study. Patients were followed from the time of admission to the time of discharge and their outcomes noted.

Data on maternal age, gestational age at diagnosis, gestational age at delivery, mode of delivery and diabetes management were collected, as well as data on birth weight, Apgar scores at one minute and five minute, neonatal complications like hypoglycaemia, hyperbilirubinaemia, respiratory distress syndrome, macrosomic baby and intensive care unit (NICU) admission were also collected and analysed.

At this institution, in all the pregnant ladies irrespective of high risk for GDM, the universal screening test done is the 50-g oral glucose challenge test (GCT), administered between 24 and 28 weeks of pregnancy. Also those women who had their antenatal check-up done outside and those who were missed for screening during 24-28 weeks were advised to do GCT during antenatal checkup in this institution. Women with an abnormal GCT result ie, blood glucose levels $\geq 140 \mathrm{mg} / \mathrm{dL}$ after two hours of oral glucose further received a 100-g, three hour oral glucose tolerance test (OGTT). If two or more values were abnormal, the patient was admitted as GDM and five-profile blood sugar was carried out which included the following samples: Fasting, pre-lunch, two hour post lunch, pre-dinner and two hour post dinner. Patients were treated with Metformin or insulin or combination of both the drugs depending upon the consultants' discretion and their five sugar profile report during antenatal period. The usual starting dose of Metformin was $500 \mathrm{mg}$ to $1500 \mathrm{mg}$ daily in divided doses and insulin dose was individualized and adjusted according to need of the patient. The goal of glycaemic control was to achieve pre-prandial blood sugar of 95$105 \mathrm{mg} / \mathrm{dL}$ and post-prandial blood sugar of $\leq 140 \mathrm{mg} /$ $\mathrm{dL}^{8}$. Patients with controlled GDM were allowed to go beyond the $38^{\text {th }}$ completed weeks. None, however, were allowed to go beyond 40 weeks of pregnancy. Induction of labour was carried out at term pregnancies and those associated with gestational hypertension. Elective caesarean section was done for diabetics with foetal macrosomia and emergency caesarean section for obstetrical indications.

Euglycaemia was achieved during labour and prior to elective caesarean section. Blood glucose concentration was measured every two hours in latent phase and every hourly in active phase of labour; blood glucose concentration higher than $120-140 \mathrm{mg} / \mathrm{dL}$ was treated with an infusion of intravenous short acting regular insulin and dose adjusted to maintain the blood glucose concentration between $70-110 \mathrm{mg} / \mathrm{dL}^{9}$.

After delivery, neonates were admitted to the newborn nursery unless they required intensive care. Glucose monitoring was performed for all neonates born to patients with GDM. The monitoring was done with a glucometer and done at 0, 1, 2, 3, 6, 12, 24, 36 and 48 hours of life $\mathrm{e}^{10}$.

Since there is increased risk of development of type $2 \mathrm{DM}$ in patients of GDM ${ }^{11}$, all the GDM patients after their delivery and upon their discharge, were advised to perform a $75 \mathrm{~g} \mathrm{GTT} \mathrm{at} \mathrm{6-8} \mathrm{weeks} \mathrm{postpartum.}$

For this study the operational definitions are:

- Macrosomia is considered as a birth weight of $\geq 4000 \mathrm{~g}$;

- Intrauterine growth restriction (IUGR) is considered if birth weight is less than $2500 \mathrm{~g}$ for term pregnancies;

- Neonatal hyperbilirubinaemia if neonatal serum bilirubin level exceeding $12 \mathrm{mg} / \mathrm{dL}$

- Neonatal hypoglycaemia if capillary heel blood glucose levels is $\leq 40 \mathrm{mg} / \mathrm{dL}$.

Other neonatal complications like hypocalcaemia, respiratory distress syndrome (RDS) including transient tachypnoea were considered and stay of $\geq 24$ hours in neonatal intensive care unit (NICU) were also obtained from the medical records. Apgar score taken at one minute and five minutes were obtained from the birth chart.

Data was analysed using Microsoft Excel version 7 on personal computer and subjected to descriptive analysis.

\section{RESULTS}

During the study period, a total of 2845 deliveries were conducted in the Department of Obstetrics and Gynaecology at KMCTH, out of which 45 (1.58\%) patients were diagnosed as GDM. The overall mean age of GDM patients in this study was $30.02 \pm 3.513$ years; likewise, the mean parity was $1.71 \pm 0.757$ (Table 1 ). Most of the cases were diagnosed at 24-28 weeks of gestation and 
the mean gestational age at time of diagnosis was $26.82 \pm 2.405$ weeks. Similarly, the gestational age (GA) at the time of delivery was above 38 weeks, mean GA being 38.64 \pm 0.85 (Table 2). Lower segment caesarean section (LSCS) was performed in 19 (42.2\%) cases (Table 2). Nine patients (20\%) developed gestational hypertension
(Table 3). On the other hand, three (6.6\%) neonates were admitted to NICU for sepsis screening because their mother had prelabour rupture of membrane. Three neonates had jaundice but did not require phototherapy. Four neonates $(8.89 \%)$ had hypoglycaemia and two (4.44\%) had respiratory distress syndrome (Table 4).

Table 1: Characteristics of women with Gestational Diabetes Mellitus

\begin{tabular}{lcc}
\hline \multicolumn{1}{c}{ Characteristics } & Number of cases $(\mathbf{n}=\mathbf{4 5})$ & Percentage \\
\hline Age in years & 5 & 11.1 \\
$20-25$ & 25 & 55.6 \\
$26-30$ & 15 & 33.3 \\
$31-35$ & $30.02 \pm 3.513$ & 40 \\
Mean age \pm SD (years) & & 60 \\
Parity & 18 & \\
Primipara & 27 & 75.6 \\
Multipara & $1.71 \pm 0.757$ & 24.4 \\
Mean parity \pm SD & & \\
Gestational age (GA) at the time of & & \\
diagnosis (weeks) & 34 & \\
24-28 & 11 & \\
29-32 & $26.82 \pm 2.4505$ & \\
Mean GA \pm SD & & \\
\hline
\end{tabular}

Table 2: Data on labour and delivery

\begin{tabular}{lcc}
\hline \multicolumn{1}{c}{ Characteristics } & Number $(\mathbf{N}=\mathbf{4 5})$ & Percentage \\
\hline Gestational age(GA) at delivery & 2 & 4.45 \\
Preterm(<37 weeks) & 43 & 95.55 \\
Term(>37weeks) & $38.64 \pm 0.85$ & 44.45 \\
Mean GA \pm SD & & 42.22 \\
Mode of delivery & 20 & 13.33 \\
Normal delivery & 19 & \\
Lower segment caesarean section(LSCS) & 6 & \\
Vacuum extraction & & \\
Type of LSCS & 10 & \\
Emergency & 9 & \\
Elective & & \\
Indications of LSCS & 4 & \\
Macrosomia & 2 & \\
Cephalopelvic disproportion & 6 & \\
Foetal distress & 2 & \\
Failed induction & 3 & \\
Previous LSCS & 1 & \\
Previous LSCS with PROM & 1 & \\
GDM with malpresentation & & \\
\hline
\end{tabular}


Bajracharya A et al.

Table 3: Maternal complications during antenatal period

\begin{tabular}{lcc}
\hline Complications & Frequency $(\mathbf{n}=\mathbf{1 6})$ & Percentage \\
\hline Gestational hypertension & 9 & 20 \\
Preterm labour & 2 & 4.44 \\
\hline Prelabour rupture of membrane & 3 & 6.67 \\
\hline Pregnancy with Urinary Tract infection & 2 & 4.44 \\
\hline
\end{tabular}

Table 4: Neonatal Complications

\begin{tabular}{lcc}
\multicolumn{1}{c}{ Characteristics } & Number (N=17) & Percentage \\
Macrosomia & 4 & 8.89 \\
Hypoglycaemia & 4 & 8.89 \\
\hline Hyperbilirubinaemia & 3 & 6.67 \\
Respiratory distress syndrome & 2 & 4.44 \\
\hline IUGR & 1 & 2.22 \\
*Admission in NICU>24hrs. & 3 & 6.67 \\
Shoulder dystocia & & \\
Congenital anomalies & & \\
Still births & & \\
\hline
\end{tabular}

*Neonates were admitted to NICU for sepsis screening as their mother had pre-labour rupture of membrane.

Table 5: Neonatal outcomes

\begin{tabular}{lcc}
\hline Characteristics & Number $(\mathbf{N}=\mathbf{4 5})$ & Percentage \\
Apgar score at $\mathbf{5}$ minutes & & 95.56 \\
$\geq 7$ & 43 & 4.44 \\
$\leq 6$ & 2 & \\
Mean Apgar \pm SD & $8 \pm 1$ & \\
Mean birth weight $(\mathrm{g}) \pm \mathrm{SD}$ & $3329.33 \pm 394.7$ & \\
\hline
\end{tabular}

\section{DISCUSSION}

GDM has been recognized as a clinical entity for the past 50 years $^{12}$ and the GDM prevalence has been reported variably from 1.4 to $14 \%$ worldwide, differently among racial and ethnic groups. Prevalence is higher in Blacks, Latino, Native Americans and Asian women than White women ${ }^{13}$. In this study, the prevalence of GDM was $1.58 \%$ which is similar to the studies done around the world ${ }^{9}$ but slightly higher than the study done by Paban $\mathrm{K}$ et $\mathrm{al}^{14}$, at the Patan Hospital where the prevalence was only $0.2 \%$. Nilofer ${ }^{15}$ in Davengere, Karnataka, performed a similar study and found a prevalence rate of $6 \%$ and Wahi et $\mathrm{al}^{16}$ from Jammu found a prevalence rate of $6.94 \%$. Our study revealed that the most common complications seen in GDM mother was gestational hypertension (20\%) followed by prelabour rupture of membrane (PROM; 6.67\%) and preterm labour (4.4\%). Similar complications were seen in the study done by Kalra et $\mathrm{al}^{17}$, where complication seen in GDM patients were gestational hypertension (36.4\%) and PROM (18.1\%). Many studies have found high caesarean delivery rates in GDM patients despite good maternal glucose control during pregnancy ${ }^{11,18,19}$. Malak ${ }^{20}$ from
Saudi Arabia found LSCS rate of $21.6 \%$ and spontaneous vertex deliveries of $74.6 \%$ in the GDM patients however, LSCS rate in this study was $42.2 \%$ and normal delivery $44.4 \%$.The main indications for LSCS in this study were maternal gestational hypertension, macrosomia, nonreassuring foetal heart tracing, failure to progress and previous history of caesarean section. Montoro et al ${ }^{21}$ have demonstrated GDM as a risk factor for hypertension, Type 2 Diabetes Mellitus and maternal complications like preterm labour and caesarean sections. Most of the study shows foetal macrosomia in $10-20 \%$ of infants born to GDM mothers ${ }^{22}$. In one study done by Priyanka $\mathrm{K}$ et $\mathrm{al}^{17}$, demonstrated $18.1 \%$ of newborns of GDM mothers were macrosomics, similarly, Hong et $\mathrm{al}^{23}$, also found an incidence of $6.5 \%$ of macrosomia in the GDM patients which is in concordance with this study where the incidence is $8.8 \%$. Many complications of pregnancy that are commonly associated with GDM such as polyhydramnios, oligohydramnios, congenital anomalies, shoulder dystocia and still births which were not found in this study. The reason might be due to universal GDM screenings done during antenatal period, early recognition of macrosomia and planned elective 
LSCS done for the same in order to prevent shoulder dystocia and maintenance of strict euglycaemia with proper management of GDM conducted in this institution. In GDM, increased numbers of pregnancy risk factors and foetal complications appear to cause significant numbers of NICU admission $>24$ hours. The rate of NICU admission (6.67\%) and Apgar score $\leq 6$ at five minutes was only $4.44 \%$ in this study for GDM neonates which is lower than $28.7 \%$ reported in one study done by Ostlund I et $\mathrm{al}^{24}$. Randomized clinical trials confirmed that treated GDM patients would have reduced risks of having neonatal birth complications as well as blood pressure disorders in the mothers ${ }^{25}$. Some studies concluded that even very mild alterations in glucose tolerance can result in abnormal foetal growth which can be prevented by simple but aggressive control of blood sugars in order to ameliorate many complications for the mother and the baby ${ }^{26}$.

\section{CONCLUSION}

The management of GDM has altered markedly in recent years. This study is important in providing information about the maternal and neonatal outcomes of gestational diabetes. By proper monitoring and good glycaemic control during the antenatal period, the adverse maternal and neonatal complications of gestational diabetes mellitus can be reduced. Hence, more efforts to assure early recognition and strict sugar control during pregnancy are recommended.

\section{REFERRENCES}

1. American Diabetes Association. Diagnosis and classification of diabetes mellitus. Diabet Care. 2011;34(1):S62-69.

2. Jimennez MoLeon J, Bueno-Cavanillas A, LunaDel-Castillo JD, Lardelli-Claret P, Garcia-Martin M, Galvez-Valgas R. Predictive value of screen for GDM, Influence of associated risk factors. Acta Obstet Gynecol. 2000;79:991-8.

3. Tamas G, Kerenyi Z. Gestational diabetes: current aspects on pathogenesis and treatment. Exp Clin Endocrinol Diabet. 2001;109Suppl2:S400-S411.

4. HAPO Study Cooperative Research Group; Metzer $B E$, Lowe LP, Dyer AR, Trimble ER, Chaovarindr $U$, et al. Hyperglycemia and adverse pregnancy outcomes. N Engl J Med. 2008;358(19):1991-2002.

5. Dornhost A, Pateson EM, Nicholls JS, Wadsworth J, Chiu DC, Elkeles RS, et al. High Prevalence of GDM in women from ethnic minority groups. Diabet Med.1992;9:820-5.

6. Moses RG. The recurrence rate of GDM in subsequent pregnancies. Diabet Care. 1996;19:1348.

7. Crowther CA. Effect of treatment of gestational diabetes on outcomes. N Engl J Med. 2005;352:2477.

8. American Diabetes Association. Standard of Medical Care in Diabetes. Diabet Care. 2012 Jan;35 Suppl 1:S11-S63.

9. Gillmer MDG, Hurley PA. Diabetes and endocrine disorders in pregnancy. In: Edmonds DK (editor). Dewhurrst's textbook of Obstetrics and Gynaecology for postgraduates. 6th ed. Oxford: Blackwell Science; 1999. p. 197-209.

10. Cloherty PJ, Eichenwald CE, Hansen RA, Stark RA. Diabetes Mellitus. Prenatal Assessment and Conditions. Manual of Neonatal Care. 7th ed. Lippincott Williams and Wilkins; 2012. p17.
11. Schmidt MI, Duncan BB, Reichelt AJ, Branchtein $L$, Matos MC, Costa e Forti A, et al. Gestational diabetes mellitus diagnosed with a 2 hour $75 \mathrm{~g}$ oral glucose tolerance test and adverse pregnancy outcomes. Diabet Care. 2001;24(7):1151-5.

12. Jensen DM, Sorensen B, Feiberg-Jorgensen N, Westergaard JG, Beck-Neilsen H. Maternal and perinatal outcomes in 143 Danish women with gestational diabetes mellitus and 143 controls with a similar risk profile. Diabet Med. 2000 Apr;17(4):2816.

13. Centers for Disease Control. Prenatal Care and Pregnancies Complicated by Diabetes. US Reporting Areas, 1989. MMWR CDL Sueveill Summ. 1993;42:119-22.

14. Sharma KP, Shrestha A. Gestational Diabetes Mellitus: A Prospective Study. J South Asian Fed Obstet Gynaecol. 2010 May-Aug;2(2):109-3.

15. Nilofer AR, Raju VS, Dakshayani BR, Zaki SA. Screening in high-risk group of gestational dibetes mellitus with its maternal and fetal outcomes. Ind J Endocrinol Metab. 2012;16:74-8.

16. Wahi P, Dogra V, Jandial K, Bhagat R, Gupta R, Gupta $S$, et al. Prevalence of gestational diabetes mellitus and its outcomes in Jammu region. J Assoc Physicians Ind. 2011;59:227-30.

17. Kalra $P$, Kachhwaha $C P$, Singh HV. Prevalence of gestational diabetes mellitus and its outcome in western Rajasthan. Ind J Endocrinol Metab. 2013;17:677-80.

18. Sendag F, Terek MC, Itil IM, Oztekin K, Bilgin O. Maternal and perinatal outcomes in women with gestational diabetes mellitus as compared to nondiabetic controls. J Reprod Med. 2001 Dec;46(12):1057-62. 
19. Tan PC, Ling LP, Omar SZ. The 50-g glucose tolerance challenge test and pregnancy outcome in a multiethnic Asian population at high risk for gestational diabetes. Int J Gynecol Obstet. 2009 Apr;105(1):50-5.

20. Al-Hakeem MM. Pregnancy Outcome of Gestational Diabetic Mothers: Experience In A Tertiary Center. J Fam Com Med. 2006 May-Aug;13(2):55-9.

21. Montoro MN, Kjos SL, Chandler M, Peters RK, Xiang $\mathrm{AH}$, Buchana TA. Insulin resistance and preeclampsia in gestational diabetes mellitus. Diabet Care. 2005;28:1995-2000.

22. Penninson E, Egerman RS. Perinatal outcomes in gestational diabetes: a comparison of criteria for diagnosis. Am J Obstet Gynecol. 2001;184:1118-21.

23. Hong JU, Rumbold AR, Wilson KJ, Crowther CA.
Borderline gestational diabetes mellitus and pregnancy outcomes. BMC Pregnancy Childbirth. 2008;8:31.

24. Ostlund I, Hanson U, Bjorklund A, Hjertberg R, Eva $\mathrm{N}$, Nordlander $\mathrm{E}$, et al. Maternal and fetal outcomes if gestational impaired glucose tolerance is not treated. Diabet Care. 2003 Jul;26(7):2107-11.

25. Bonomo M, Corica D, Mion E, Goncalves D, Motta G, Merati $\mathrm{R}$, et al. Evaluating the therapeutic approach in pregnancies complicated by borderline glucose intolerance: a randomized clinical trial. Diabet Med. 2005 Nov;22(11):1536-41.

26. Landan $M B$, spong $C Y$, Thom $E$, Carpenter MW, Ramin SM, Casey B, et al; Eunice Kennedy Shriver Medicine Units Network. A multicenter, randomized trial of treatment for mild gestational diabetes. $\mathrm{N}$ Eng J Med. 2009 Oct;361(14):1339-48. 